\title{
Giant gastrointestinal stromal tumor of the vermiform appendix: A case report
}

\author{
MANABU KANEKO $^{1}$, KAZUSHIGE KAWAI ${ }^{1}$, KOJI MURONO ${ }^{1}$, TAKESHI NISHIKAWA ${ }^{1}$, KAZUHITO SASAKI ${ }^{1}$, \\ KENSUKE OTANI $^{1}$, KOJI YASUDA ${ }^{1}$, TOSHIAKI TANAKA ${ }^{1}$, TOMOMICHI KIYOMATSU ${ }^{1}$, KEISUKE HATA ${ }^{1}$, \\ HIROAKI NOZAWA ${ }^{1}$, SOICHIRO ISHIHARA ${ }^{1}$, AKIMASA HAYASHI ${ }^{2}$, AYA SHINOZAKI-USHIKU ${ }^{2}$, \\ MASASHI FUKAYAMA $^{2}$ and TOSHIAKI WATANABE ${ }^{1}$
}

Departments of ${ }^{1}$ Surgical Oncology and ${ }^{2}$ Pathology, Faculty of Medicine, The University of Tokyo, Tokyo 113-8655, Japan

Received December 20, 2016; Accepted March 4, 2017

DOI: $10.3892 /$ mco.2017.1334

\begin{abstract}
Gastrointestinal stromal tumors (GISTs) of the vermiform appendix are rare, measuring $<3 \mathrm{~cm}$ in $82.4 \%$ of the reported cases. Neoadjuvant therapy with the receptor tyrosine kinase inhibitor imatinib mesylate has the potential to improve resectability and organ preservation rates in locally advanced or metastatic/recurrent GISTs. We herein report the case of a 67-year-old male patient with an unusually large GIST $(22 \mathrm{~cm}$ in diameter) of uncertain origin in the right lower abdominal quadrant, with a solitary peritoneal metastasis. Due to the size of this GIST and presence of metastatic disease, neoadjuvant therapy with imatinib (400 mg/day orally) was administered. Follow-up imaging studies revealed marked shrinkage of the primary and metastatic tumors. Subsequently, laparoscopic exploration revealed that the main tumor originated from the tip of the vermiform appendix, and that the peritoneal metastasis was located in the ascending mesocolon. The patient underwent laparoscopic appendectomy and excision of the peritoneal metastasis, without tumor rupture. Therefore, in appropriately selected patients, neoadjuvant imatinib for borderline resectable or oligometastatic GISTs may be a reasonable choice.
\end{abstract}

\section{Introduction}

Gastrointestinal stromal tumors (GISTs) are the most common mesenchymal tumors of the GI tract. GISTs most commonly develop in the stomach (50-60\%) and small intestine (30-35\%), although they may also arise in the large intestine $(5-10 \%)$, esophagus $(<1 \%)$ and, rarely, in locations outside the GI tract (mesentery, omentum and retroperitoneum, <5\%) $(1,2)$. GISTs

Correspondence to: Dr Manabu Kaneko, Department of Surgical Oncology, Faculty of Medicine, The University of Tokyo, 7-3-1 Hongo, Bunkyo-ku, Tokyo 113-8655, Japan

E-mail: m.kaneko@fancy.ocn.ne.jp

Key words: gastrointestinal stromal tumor, vermiform appendix, imatinib, neoadjuvant therapy originating from the vermiform appendix are rare, constituting only $0.1 \%$ of all GISTs, and they are sized $<3 \mathrm{~cm}$ in $82.4 \%$ of the reported cases. Several previous studies have reported the usefulness of neoadjuvant therapy with imatinib mesylate, a selective tyrosine kinase inhibitor, in locally advanced or metastatic/recurrent GISTs (3). We herein report a case of a giant GIST of the appendix with a single peritoneal metastasis in a 67-year-old man, who subsequently underwent neoadjuvant imatinib therapy, which resulted in effective tumor shrinkage, allowing minimally invasive laparoscopic surgery.

\section{Case report}

A 67-year-old man with a 6-month history of lower abdominal pain due to a large abdominal mass lesion was referred to the Department of Surgical Oncology (University of Tokyo Hospital, Tokyo, Japan) in February, 2014. The patient's medical history included chronic rhinosinusitis 30 years prior and endoscopic colonic polypectomy 1 year prior. A physical examination revealed that the patient was afebrile, with normal vital signs. Mild tenderness was detected in the lower abdomen, with a palpable mass sized $>20 \mathrm{~cm}$. Laboratory tests revealed mildly decreased hemoglobin and albumin levels (11.0 and $3.4 \mathrm{~g} / \mathrm{dl}$, respectively), mildly elevated C-reactive protein level (1.39 mg/dl), normal white blood cell count $(4,700 / \mu \mathrm{l})$ and normal carcinoembryonic antigen level $(2.1 \mathrm{ng} / \mathrm{ml}$; normal level, $<5 \mathrm{ng} / \mathrm{ml}$ ). An abdominal computed tomography (CT) scan revealed a large mass $(220 \times 180 \times 100 \mathrm{~mm})$ with heterogeneous enhancement in the right lower abdominal quadrant. Due to its size, the tumor origin was unclear. A CT scan also revealed another mass $(70 \times 65 \times 50 \mathrm{~mm})$ located cranially to the main tumor (Fig. 1A and B). Esophagogastroduodenoscopy, colonoscopy and capsule endoscopy revealed no evidence of other neoplastic lesions. CT-guided fine-needle biopsy showed bundles of spindle cells stained positive for c-KIT (Fig. 2), with 5 mitotic cells per 50 high-power fields, and a Ki-67 (MIB-1) labeling index of $>10 \%$. There was no desmin or protein $\mathrm{S} 100$ immunoreactivity. On the basis of these findings, the tumors were diagnosed as GISTs, possibly arising from the ileum, cecum or appendix, with a peritoneal metastasis. The case was determined to be high-risk according to criteria proposed by Miettinen et al (1) and Joensuu et al (4). 

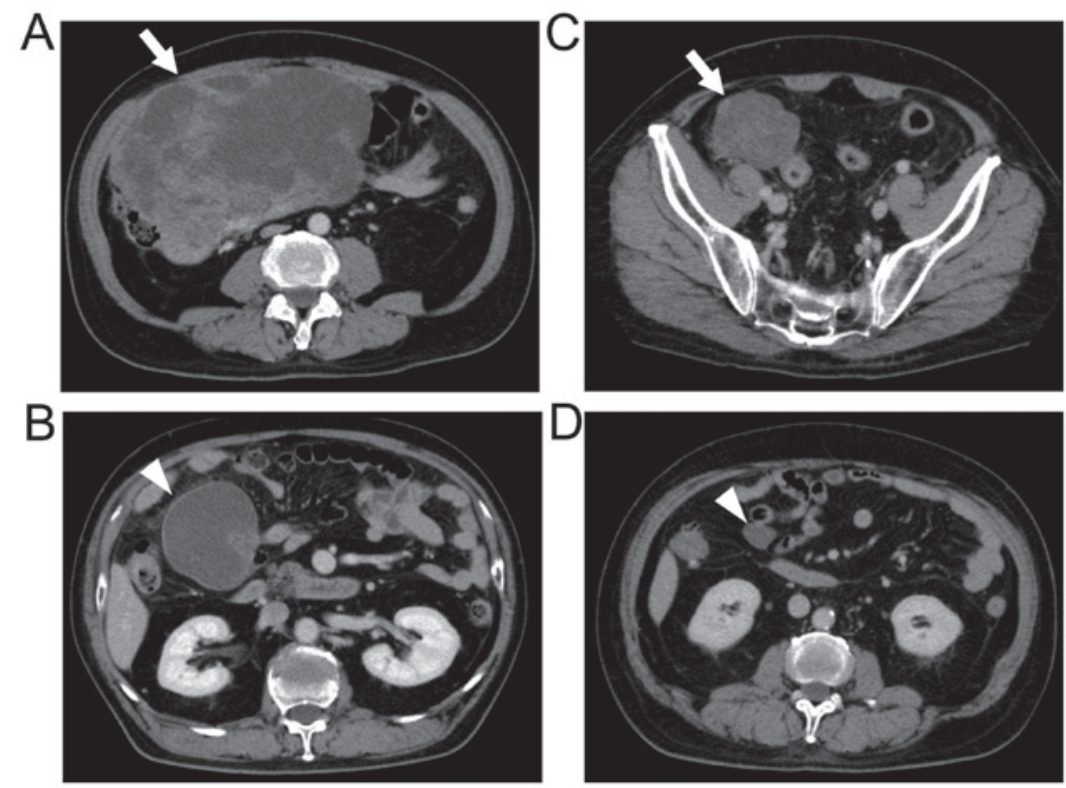

Figure 1. Coronal view of an abdominal computed tomography scan with contrast. (A and B) Prior to neoadjuvant therapy, a 22-cm tumor was identified in the right lower abdomen (A, arrow) and a 7-cm tumor was found to be located cranially to the main tumor (B, arrowhead). (C and D) Following neoadjuvant therapy, the primary and metastatic tumors shrank to $6.3 \mathrm{~cm}(\mathrm{C}$, arrow) and $1.9 \mathrm{~cm}(\mathrm{D}$, arrowhead), respectively.
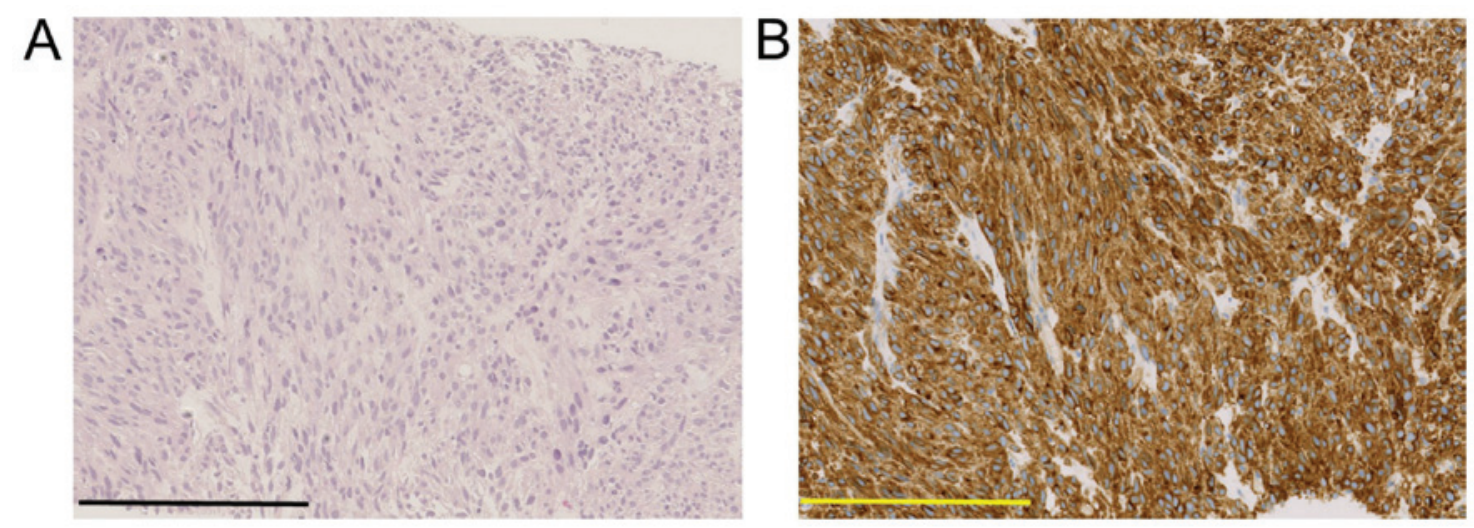

Figure 2. Histomicrographs of the biopsied specimen. (A) Hematoxylin and eosin staining. The tumor was composed of spindle cells. (B) On immunohistochemical examination, the spindle tumor cells stained positive for c-KIT. Bars, $250 \mu \mathrm{m}$.

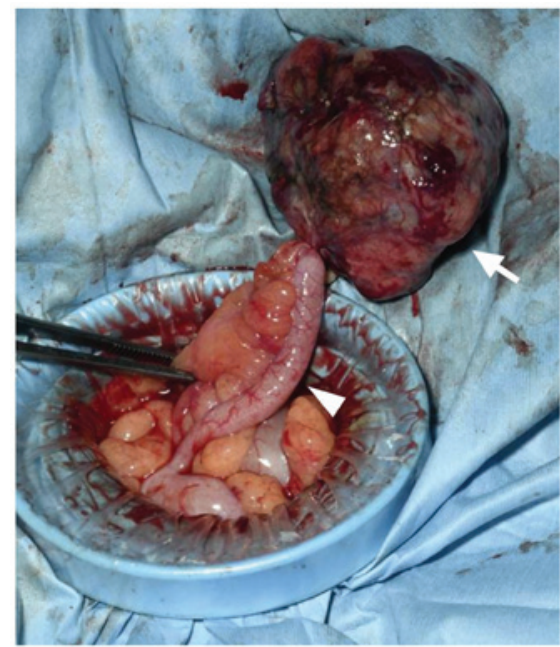

Figure 3. Intraoperative findings. A sizeable appendiceal gastrointestinal stromal tumor (arrow) originated from the tip of the vermiform appendix (arrowhead).
Due to the size of the tumor and the presence of peritoneal metastasis, neoadjuvant therapy with imatinib $400 \mathrm{mg}$ /day was initiated; no imatinib-related adverse events were detected during treatment. Follow-up imaging studies revealed a gradual decrease in tumor size. After 26 months of imatinib treatment, a final evaluation revealed $63 \times 55-\mathrm{mm}$ and $22 \times 20-\mathrm{mm}$ masses, without a significant change in size over the prior 3 months (Fig. 1C and D). Subsequently, laparoscopic exploration revealed that the main tumor originated from the tip of the vermiform appendix (Fig. 3) and that the peritoneal metastasis was located in the ascending mesocolon. Consequently, appendectomy and grossly complete resection of the peritoneal metastatic tumor were laparoscopically performed, without tumor rupture. The gross specimen of the main tumor was a whitish-gray hemorrhagic mass, sized 80x60x55 mm, growing outward from the tip of the appendix (50 mm in length, $10 \mathrm{~mm}$ in diameter). The peritoneal metastatic tumor (22x18x14 mm) had the same gross appearance. Microscopic examination 


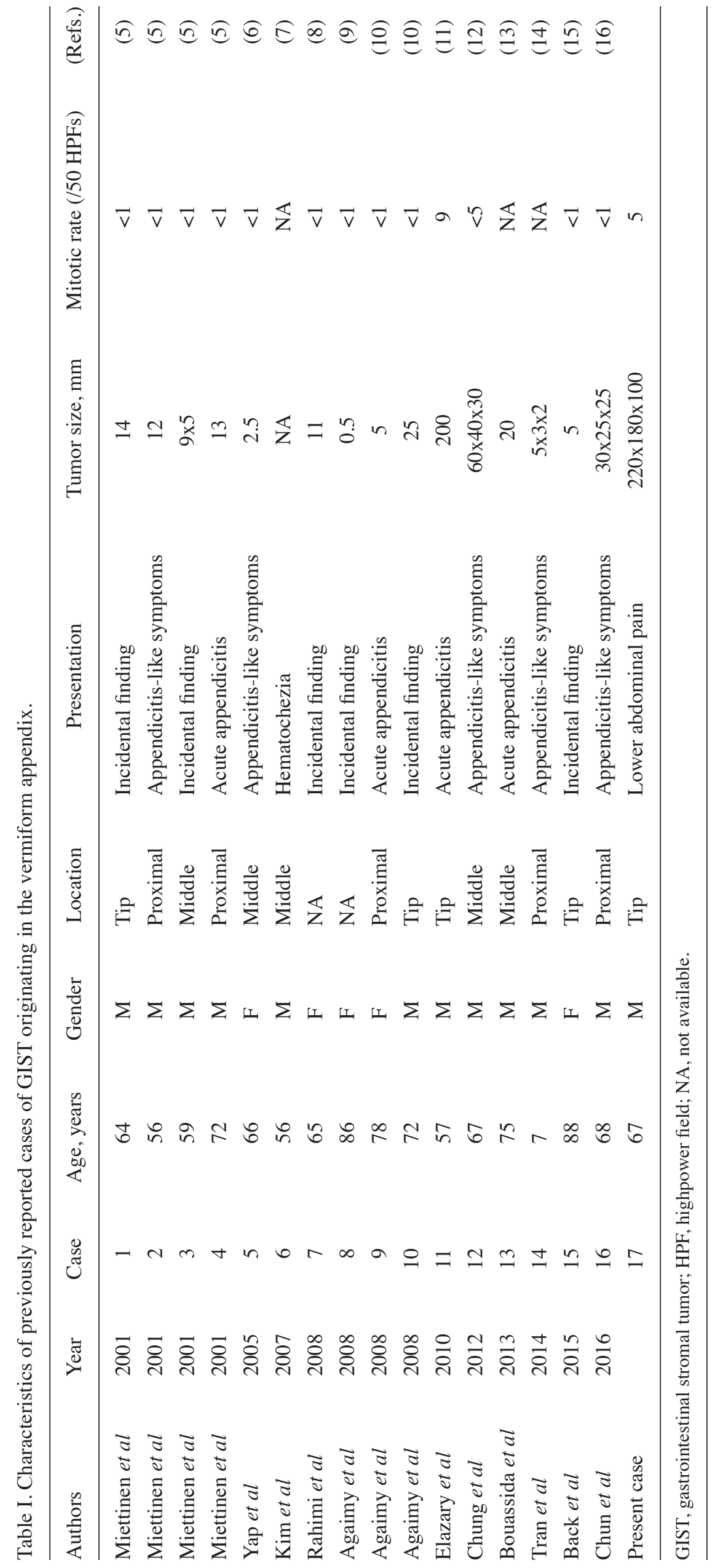


revealed no lymphovascular invasion and a mitotic count of 2/50 high-power fields in the main tumor. The postoperative course was uneventful and the patient was discharged without complications. The patient commenced imatinib treatment 1 month after surgery and he remained alive and disease-free at the last follow-up, 6 months after the surgery. The date of the last follow-up was 8th March, 2017.

Written informed consent was obtained from the patient for the publication of the case details and associated images.

\section{Discussion}

GISTs of the vermiform appendix constitute only $0.1 \%$ of all GISTs (1), with only 16 cases reported in the English literature to date (5-16). The characteristics of these 17 GIST cases (including the present case) are listed in Table I. The median patient age was 67 years (range, 7-88 years) and the male:female ratio was 2.4:1. The tumor originated from the proximal end of the appendix in 5 cases, from the middle in 5 , from the tip in 5, and information on the origin was unavailable in 2 cases. Seven patients presented with appendicitis-like symptoms without histological evidence of acute appendicitis, suggesting that the symptoms were caused by the tumor. Two patients presented with peritonitis, which was caused by acute appendicitis in one case, and by formation of a peri-appendiceal abscess in the other case. The remaining 6 tumors were incidentally discovered during surgery for other diseases or during autopsy. The median size was $12.5 \mathrm{~mm}$ (range, 0.5-220 mm). To the best of our knowledge, the present case represents the largest appendiceal GIST reported to date. The tumor was so large that the patient experienced pain in the entire lower abdomen, and the origin of the tumor could not be determined by preoperative investigation. Furthermore, our case was classified as high-risk according to the criteria of Joensuu et al (4), whereas 14 of the 17 reported appendiceal GISTs (82.4\%) were classified as very low- or low-risk.

Complete surgical resection is the only curative treatment for GIST. However, the introduction of imatinib therapy, which is established as an adjuvant therapy following surgery in high-risk cases, as well as first-line therapy in metastatic cases, has markedly improved the cure rate and the prognosis (17). In addition, several studies have demonstrated that neoadjuvant therapy with imatinib for locally advanced or metastatic/recurrent GISTs may offer advantages, such as cytoreduction, in order to facilitate $\mathrm{R} 0$ resection, the potential for organ preservation, a less invasive surgical approach and a lower risk of intraoperative tumor rupture $(3,18,19)$. As the present case included a giant tumor with peritoneal metastasis, tumor rupture or macroscopic residual tumor (R2 resection) was a possible risk. Thus, neoadjuvant imatinib was administered to decrease the tumor size in order to achieve complete resection (R0/R1) (20). After 26 months of imatinib treatment, the patient underwent laparoscopic appendectomy and gross complete resection of the peritoneal metastatic tumor, without tumor rupture. The optimal duration of neoadjuvant therapy for GIST remains controversial. Theoretically, neoadjuvant therapy may be continued until the tumor size decreases or its metabolic activity reaches a plateau phase, but the development of resistance due to secondary KIT mutations during this stage remains a risk (21). The duration of neoadjuvant imatinib therapy in a metastatic setting should be case-based, depending on the response to treatment. The main aim of neoadjuvant treatment is to convert unresectable/borderline-resectable disease to resectable disease.

In conclusion, appendiceal GISTs sized $>10 \mathrm{~cm}$ are extremely rare. We herein reported a case of an unusually large appendiceal GIST $(22 \mathrm{~cm})$ with a solitary peritoneal metastasis, which was successfully treated with neoadjuvant imatinib therapy and laparoscopic surgery. Therefore, in appropriately selected patients, neoadjuvant imatinib for borderline resectable or oligometastatic GISTs may be a reasonable choice.

\section{References}

1. Miettinen M and Lasota J: Gastrointestinal stromal tumors: Pathology and prognosis at different sites. Semin Diagn Pathol 23: 70-83, 2006.

2. Joensuu H, Hohenberger P and Corless CL: Gastrointestinal stromal tumour. Lancet 382: 973-983, 2013.

3. Ford SJ and Gronchi A: Indications for surgery in advanced/metastatic GIST. Eur J Cancer 63: 154-167, 2016.

4. Joensuu H: Risk stratification of patients diagnosed with gastrointestinal stromal tumor. Hum Pathol 39: 1411-1419, 2008.

5. Miettinen M and Sobin LH: Gastrointestinal stromal tumors in the appendix: A clinicopathologic and immunohistochemical study of four cases. Am J Surg Pathol 25: 1433-1437, 2001.

6. Yap WM, Tan HW, Goh SG and Chuah KL: Appendiceal gastrointestinal stromal tumor. Am J Surg Pathol 29: 1545-1547, 2005.

7. Kim KJ, Moon W, Park MI, Park SJ, Lee SH and Chun BK: Gastrointestinal stromal tumor of appendix incidentally diagnosed by appendiceal hemorrhage. World J Gastroenterol 13: 3265-3267, 2007.

8. Rahimi K, Gologan A, Haliotis T, Lamoureux E and Chetty R: Gastrointestinal stromal tumor with autonomic nerve differentiation and coexistent mantle cell lymphoma involving the appendix. Int J Clin Exp Pathol 20: 608-613, 2008.

9. Agaimy A, Wünsch PH, Dirnhofer S, Bihl MP, Terracciano LM and Tornillo L: Microscopic gastrointestinal stromal tumors in esophageal and intestinal surgical resection specimens: A clinicopathologic, immunohistochemical and molecular study of 19 lesions. Am J Surg Pathol 32: 867-873, 2008.

10. Agaimy A, Pelz AF, Wieacker P, Roessner A, Wünsch PH and Schneider-Stock R: Gastrointestinal stromal tumors of the vermiform appendix: Clinicopathologic, immunohistochemical, and molecular study of 2 cases with literature review. Hum Pathol 39: 1252-1257, 2008.

11. Elazary R, Schlager A, Khalaileh A, Appelbaum L, Bala M, Abu-Gazala M, Khatib A, Neuman T, Rivkind AI and Almogy G: Malignant appendiceal GIST: Case report and review of the literature. J Gastrointest Cancer 41: 9-12, 2010.

12. Chung JC and Song OP: Gastrointestinal stromal tumor of the appendix. Turk J Gastroenterol 23: 303-304, 2012.

13. Bouassida M, Chtourou MF, Chalbi E, Chebbi F, Hamzaoui L, Sassi S, Charfi L, Mighri MM, Touinsi H and Sassi A: Appendiceal GIST: Report of an exceptional case and review of the literature. Pan Afr Med J 15: 85, 2013.

14. Tran S, Dingeldein M, Mengshol SC, Kay S and Chin AC: Incidental GIST after appendectomy in a pediatric patient: A first instance and review of pediatric patients with CD117 confirmed GISTs. Pediatr Surg Int 30: 457-466, 2014.

15. Back J, Jeanty J and Landas S: Gastrointestinal stromal tumor of the appendix: Case report and review of the literature. Hum Pathol Case Rep 2: 94-98, 2015.

16. Chun JM and Lim KH: Gastrointestinal stromal tumor of the vermiform appendix mimicking Meckel's diverticulum: Case report with literature review. Int J Surg Case Rep 21: 20-22, 2016.

17. Valsangkar N, Sehdev A, Misra S, Zimmers TA, O'Neil BH and Koniaris LG: Current management of gastrointestinal stromal tumors: Surgery, current biomarkers, mutations, and therapy. Surgery 158: 1149-1164, 2015.

18. Andtbacka RH, Ng CS, Scaife CL, Cormier JN, Hunt KK, Pisters PW, Pollock RE, Benjamin RS, Burgess MA, Chen LL, et al: Surgical resection of gastrointestinal stromal tumors after treatment with imatinib. Ann Surg Oncol 14: 14-24, 2007. 
19. Benjamin RS, Choi H, Macapinlac HA, Burgess MA, Patel SR, Chen LL, Podoloff DA and Charnsangavej C: We should desist using RECIST, at least in GIST. J Clin Oncol 25: 1760-1764, 2007.

20. Bauer S, Rutkowski P, Hohenberger P, Miceli R, Fumagalli E, Siedlecki JA, Nguyen BP, Kerst M, Fiore M, Nyckowski P, et al: Long-term follow-up of patients with GIST undergoing metastasectomy in the era of imatinib-analysis of prognostic factors (EORTC-STBSG collaborative study). Eur J Surg Oncol 40 412-419, 2014
21. Haller F, Detken S, Schulten HJ, Happel N, Gunawan B, Kuhlgatz J and Füzesi L: Surgical management after neoadjuvant imatinib therapy in gastrointestinal stromal tumours (GISTs) with respect to imatinib resistance caused by secondary KIT mutations. Ann Surg Oncol 14: 526-532, 2007. 